\title{
WNT5a in Colorectal Cancer: Research Progress and Challenges
}

This article was published in the following Dove Press journal:

Cancer Management and Research

\section{Guangshun Sun ${ }^{1, *}$ \\ Liangliang $\mathrm{Wu}^{\mathrm{l}, *}$ \\ Guoqiang Sun' \\ Xuesong Shi \\ Hongyong $\mathrm{Cao}^{\prime}$ \\ Weiwei Tang ${ }^{2}$}

'Department of General Surgery, Nanjing First Hospital, Nanjing Medical University, Nanjing, Jiangsu, People's Republic of China;

${ }^{2}$ Hepatobiliary/Liver Transplantation Center, The First Affiliated Hospital of Nanjing Medical University, Key Laboratory of Living Donor Transplantation, Chinese Academy of Medical Sciences, Nanjing, jiangsu, People's Republic of China

*These authors contributed equally to this work
Correspondence: Hongyong Cao; Weiwei Tang

Email caohongy6167@163.com;

1243773473twww@sina.com

\begin{abstract}
Despite the clinical development of new adjuvant and neoadjuvant chemotherapy drugs, colorectal cancer is still one of the leading causes of cancer-related death in human beings. WNT5a, an autocrine and paracrine $\beta$-catenin independent ligand, has been shown to induce tumor inhibition and carcinogenic signals, depending on the type of cancer. In patients with colorectal cancer, WNT5a triggers a variety of downstream signaling pathways, which mainly affect the migration and invasion of tumor cells. This article reviews the mechanism and therapeutic potential of WNT5a in colorectal cancer. In short, an in-depth understanding of the role of WNT5a in colorectal cancer is very helpful to better deal with this disease.
\end{abstract}

Keywords: WNT5a, colorectal cancer, WNT, therapy

\section{Introduction}

Colorectal cancer (CRC) is a dominating cancer-related health problem, which is the third most common cancer and the fourth most common cancer-related cause of death, taking up $9 \%$ of the total incidence of cancer. ${ }^{1}$ Despite the perfection of the early screening program, improvement of surgical skills, and the clinical development of chemotherapeutic drugs promote the decrease of incidence and overall mortality rate, $\mathrm{CRC}$ remains a major public hygiene matter, largely due to obesity, smoking and red meat consumption. ${ }^{1-5}$ For the research of last decades, we know that $\mathrm{CRC}$ is a heterogeneous disease with ample biological behaviors and abundant gene alteration and signal pathway changes, ${ }^{6,7}$ but the specific pathogenesis still needs to be perfected. About 5\% CRC cases have a bearing on inheritance, highly penetrant cancer syndromes, like familial adenomatous polyposis (FAP) and Lynch syndrome (LS), while up to 20 to $30 \%$ CRC cases are considered as familial aggregating. ${ }^{8}$ With the discovery of abundant genetic mutations in the course of CRC like APC germline mutation, the therapy methods targeted to mutational genes achieve great progress. 9,10

The wingless-type MMTV integration site (WNT) polygene family encodes secreted extracellular signaling proteins that regulate cell polarity, motility, and pattern during embryogenesis and tissue homeostasis. ${ }^{11}$ In vivo, the WNT family contains 19 highly conserved lipid-modified glycoproteins that function by binding to different and co-receptors such as low-density lipoprotein receptor-associated proteins (LRP5/6), crimp receptor (FZD), and associated receptor tyrosine kinase (RYK). ${ }^{12}$ Most WNT proteins range in length from $38-43 \mathrm{kDa}$, contain up to 22 conserved cysteine residues, and are highly lipid modified and glycylated. ${ }^{13} \mathrm{WNT}$ 
proteins are hydrophobic and attach primarily to the extracellular matrix. ${ }^{14}$ Studies have shown that WNT genes cannot be considered functionally equivalent, although they have similar structures, but different WNT genes play different roles in cell growth. ${ }^{15}$ WNT genes were divided into three groups: WNT1, WNT2, WNT3 and WNT3A, which induced strong transformation and an elongated refractile cell morphology; WNT6 and WNT7A, which produced weak morphological changes; and WNT4, WNT5a, WNT5B and WNT7B, which had no effect on C57MG morphology. ${ }^{16}$ Meanwhile, WNT proteins can be divided into two classes: canonical WNTs, including WNT1, WNT3A, WNT8 and WNT8B, participate in regulating WNT/ $\beta$-catenin-dependent single pathway; non-canonical WNTs, including WNT4, WNT5a, and WNT11, participate in regulating $\mathrm{WNT} / \beta$-catenindependent single pathway. ${ }^{17}$ In canonical pathway, the absence of WNT ligands causes b-catenin to be phosphorylated by a destruction complex formed by the scaffold protein Axin, APC and the kinases GSK3 $\beta$ and casein kinase $(\mathrm{CK} 1 \alpha)$, leading to the absence of nuclear $\beta$ catenin. In this state, TCF/LEF and transducing-like enhancer protein (TLE/Groucho) formed a repressive complex, which recruits HDACs to repress the target gene. When there are WNT ligands, WNT ligand binds to FZD receptor and LRP co-receptor to form a complex activating canonical pathway. LRP receptors are then phosphorylated by CK1 $\alpha$ and GSK3 $\beta$, which recruit Dishevelled (Dvl) proteins to accumulate on the plasma membrane and be activated. Dvl polymers can repress the destruction complex, which saved b-catenin and made them accumulate in the nucleus. There b-catenin formed an active complex with LEF and TCF by displacing TLE/Groucho complexes and recruitment of histone modifying co-activators. This transcriptional switch leads to changes in a variety of cellular processes. ${ }^{18-21}$ The mechanism of non-classical WNT signaling pathway is complex. At present, the two main pathways are $\mathrm{WNT} / \mathrm{Ca} 2+$ signaling pathway and WNT/PCP signaling pathway. In WNT/PCP signaling, the WNT ligands bind to the ROR-Frizzled receptor complex, which recruits the Dvl. Then the Dvl bind to the small GTPase kho. The small GTPase Rac1 and Rho together trigger ROCK (Rho kinase) and JNK, which leads to the rearrangement of the cytoskeleton and/or transcriptional responses. WNT/Ca2 + signal is initiated by phospholipase $\mathrm{C}$ activity triggered by $\mathrm{G}$ protein, which leads to intracellular calcium flow and downstream calcium-dependent cytoskeleton and/or transcriptional responses $^{22-27}$ (Figure 1). In contrast to $\beta$-catenindependent signaling, whose role in tumor progression such as CRC has been established, the function of nonclassical pathways remains unclear. ${ }^{28}$ These two singling pathways share WNT ligands, such as Dvl signal transducers and FZD receptors. ${ }^{29}$

WNT5a is located on chromosome 3P14-p21, consisting of five exons and the final exon of the 3'untranslated region encoding about $6.5 \mathrm{~km}$ base pairs, and using multiple polyadenylation signals to produce at least four discrete transcripts. ${ }^{30}$ The WNT5a gene produces two identical transcription scripts encoding two different splicing isotypes, including WNT5a-long (L) and WNT5a-short (S), ${ }^{29}$ which are realized by using variable transcription initiation sites, and the corresponding upstream sequences are called promoters $\mathrm{A}$ and $\mathrm{B}$. The former includes 18 amino acids in the n-terminal domain of the slender WNT5a-L subtype, while the latter is the truncated WNT5a-S form. ${ }^{31}$ We know that these two different splicing subtypes have different levels of expression in cancer. In adult tissues, WNT5-L is expressed in almost all tissues except adipose tissue, while WNT5a-S is only expressed in placenta and is less expressed in trachea and small intestine. $^{29}$

WNT5a is generally considered to be a key ligand for a single pathway of non-classical $\mathrm{WNT} / \beta$-catenin dependence. However, in some cases, it also activates WNT/ $\beta$-catenin-dependent single pathway. ${ }^{32}$ In WNT/ PCP signaling pathway, WNT5a can activate Dvl by forming complexes with FZD and Ror2 receptors, and furthermore, small GTP enzymes of the Rho family are activated, including RhoA and Rac, and their downstream effectors, Rho-associated protein kinase (ROCK), the actin-binding protein, Filamin $\mathrm{A}$ and c-Jun N-terminal protein kinase (JNK), and in turn PCP pathway is started. This process leads to the rearrangement of the cytoskeleton and regulating polarized cell morphology and migration within tissues. ${ }^{33-36}$ WNT5a activation of the WNT/Ca2+ signaling pathway leads to the mobilization of free intracellular calcium, which regulates many cellular processes, including actin cytoskeleton remodeling and cell motility through activation of calcium-dependent signaling molecules. ${ }^{37-41}$ In the canonical pathway, WNT5a plays two roles. On the one hand, WNT5a can activate canonical pathways to regulate embryogenesis and cell fate specificity. On the other hand, WNT5a can repress the canonical pathway 


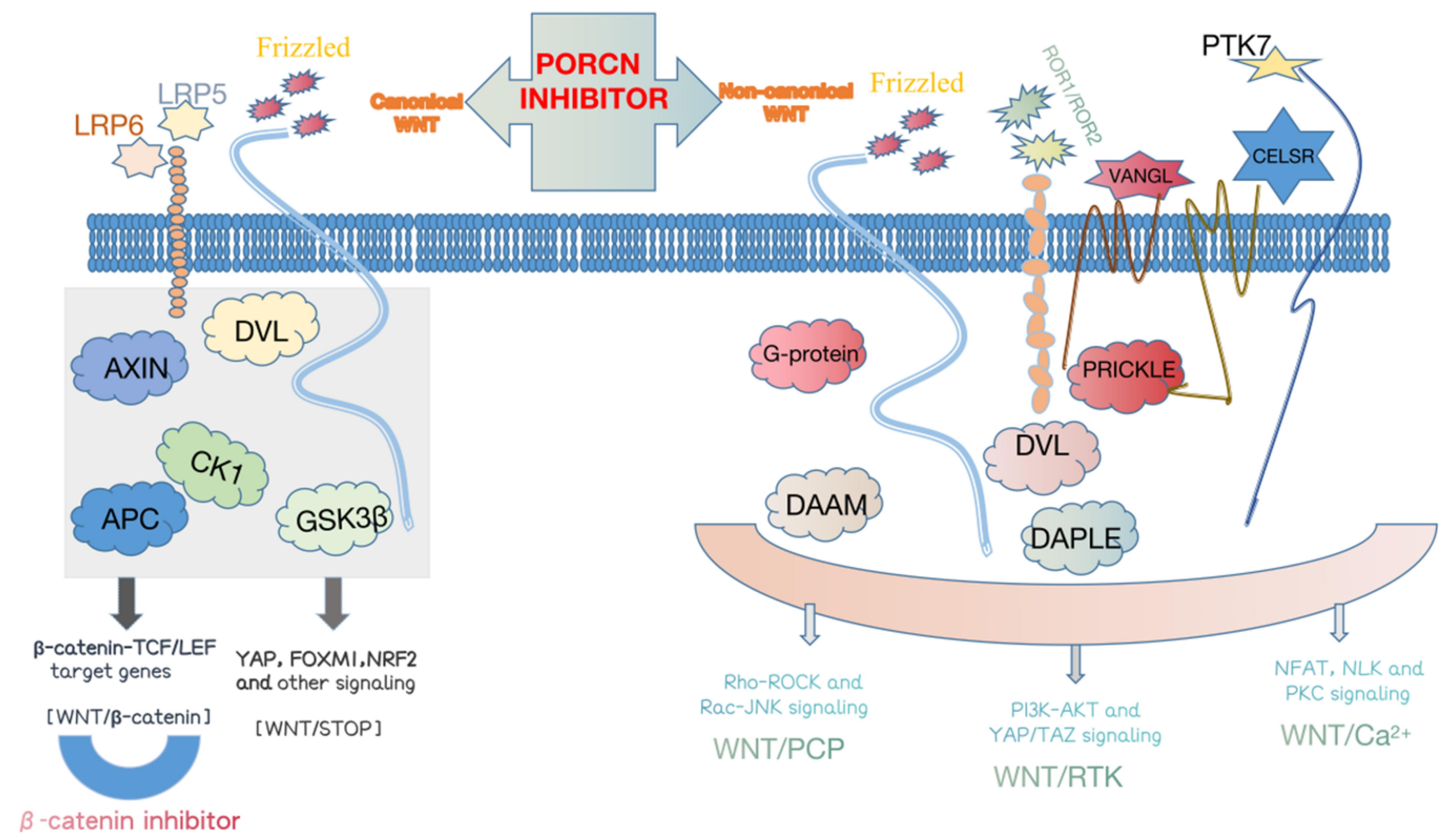

Figure I Canonical WNT signaling is transduced by the WNT/ $\beta$-catenin and WNT/STOP (stabilization of proteins) signaling cascades through Frizzled (FZD) and LRP5/6 receptors, whereas non-canonical WNT signaling is transduced by the WNT/PCP (planar cell polarity), WNT/RTK (receptor tyrosine kinase), and WNT/Ca2+ signaling cascades through FZD and/or RORI/ROR2/RYK receptors.

by promoting glycogen synthase kinase3-independent degradation of $\beta$-catenin in regulating mammalian limb development ${ }^{42,43}$ (Figure 2).

Many studies have proved that downregulation of WNT5a is associated with a poor prognosis in many types of cancers like CRC, which suggests the tumor suppressor role of WNT5a in those types of cancers. ${ }^{44}$ Thus, we imagine whether WNT5a can be a good therapeutic target of CRC in the future. This review will also conclude the current research progress and look forward to the research trends in the future and discuss the potential therapeutic value of WNT5a.

\section{Expression and Silence of WNT5a in CRC}

Previous studies have shown that WNT5a is down-regulated in brain, breast, and thyroid cancers, while up-regulated in lung, gastric, and prostate cancers. ${ }^{45-47}$ According to the related research of colorectal cancer, the expression level of WNT5a in CRC cells was negatively correlated with tumor grade of CRC patients and reintroduction of WNT5a into CRC cells resulted in inhibition of the motility and proliferation of CRC cells. ${ }^{45,48}$
In human papillomavirus (HPV)-associated colorectal cancer, the expression of WNT5a is up-regulated. ${ }^{49}$ Dong's ${ }^{50}$ research has shown that the level of WNT5a in primary tumors was higher than that in normal colon tissue. In cell line SW680, a highly metastatic human colon cancer cell line, the WNT5a is largely silent. Previous study detected that this silence had to do with the DNA methylation at the promoter of WNT5a. ${ }^{47}$ For Qian' s research, ${ }^{51}$ the level of WNT5a expression reacted to histone deacetylase(HDAC), inhibitor trichostatin $\mathrm{A}(\mathrm{TSA})$, and sodium butyrate(NaBT) goes up, but this wasnot to do with the DNA methylation inhibitor, thus they came to the conclusion that this silence of WNT5a in SW680 and SW480 was related with the histone modifications include acetylation, methylation, and phosphorylation. One point worth paying attention to in Qian et al's ${ }^{52}$ research is that HDAC stimulated the elevation of $\mathrm{WNT} / \beta$ catenin pathway while increased the expression of WNT5a.

According to a 2016 study, loss of imprinting (LOI) of the insulin-like growth factor 2 (IGF2) induced the expression of WNT5a, but the specific mechanism needs to be further explored. ${ }^{53}$ About $75 \%$ of sporadic $\mathrm{CRCs}$ are $\mathrm{CpG}$ island methylator phenotype (CIMP) - 


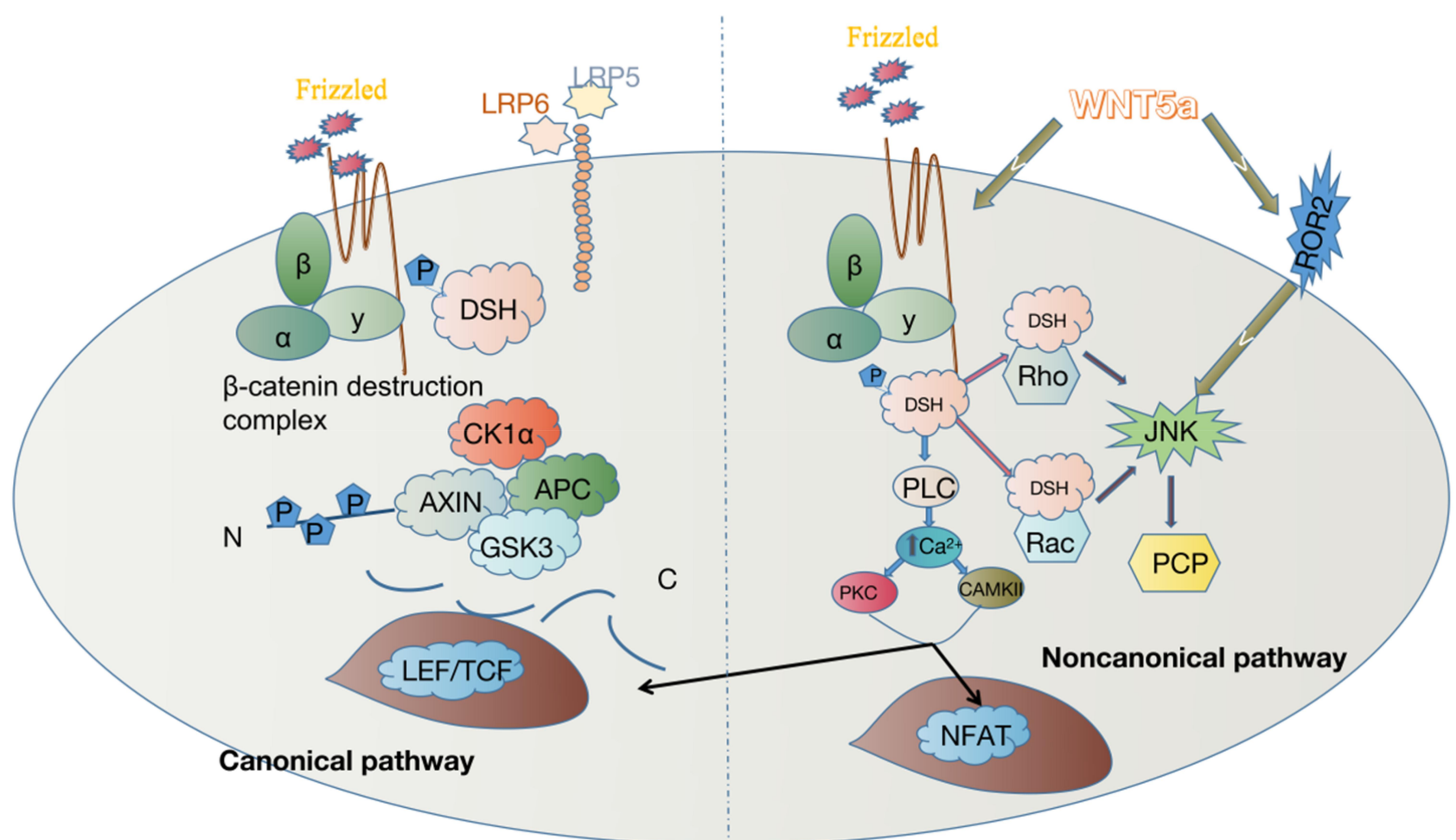

Figure 2 In WNT/PCP signaling pathway, WNT5a can activate Dvl by forming complexes with FZD and Ror2 receptors, and furthermore, small GTP enzymes of the Rho family are activated, including RhoA and Rac, and their downstream effectors, Rho-associated protein kinase (ROCK), the actin-binding protein, Filamin A and c-Jun $\mathrm{N}$-terminal protein kinase (JNK), and in turn PCP pathway is activated. This process leads to the rearrangement of the cytoskeleton and regulating polarized cell morphology and migration within tissues. ${ }^{33-36}$ WNT5a activation of the WNT/Ca2+ signaling pathway leads to the mobilization of free intracellular calcium, which regulates many cellular processes, including actin cytoskeleton remodeling and cell motility through activation of calcium-dependent signaling molecules. ${ }^{37-41}$ In the canonical pathway, WNT5a plays two roles. On the one hand, WNT5a can activate canonical pathways to regulate embryogenesis and cell fate specificity. On the other hand, WNT5a can repress the canonical pathway by promoting glycogen synthase kinase3-independent degradation of $\beta$-catenin in regulating mammalian limb development. ${ }^{42,43}$

negative (CIMP-zero or CIMP-low). ${ }^{54}$ Research has shown that the level of the DNA methylation of the promoter of WNT5a in CRC was higher than that in adenoma. $^{55}$ John's $^{56}$ research shows that extracellular calcium-sensing receptor/PTH knockout mice colons (C-/P-mice) increased the WNT/b-catenin signaling and reduced non-canonical WNT signaling, including WNT5a compared to $\mathrm{C}+/ \mathrm{P}+$ mice. Holcombe's research57 showed that the expression of WNT5a was different in different parts of normal mucosa: the expression at the base of the crypt was higher than that of lumen villi. WNT5a is involved in the process of carcinogenesis of normal mucosa. In Wang's ${ }^{58}$ study, the level of WNT5a RNA was significantly decreased in the SW480 cells line incubated in the MEM lacking all amino acid (MEM-AA), but the phosphorylation of ERK1/2 was increased, by which the hypothesis was proved that the amino acid limitation induced the phosphorylation of ERK1/2, and then down regulated the WNT5a expression.
We have known that WNT5a produces two identical transcription scripts to encode two different splice isoforms including WNT5a-long (L) and WNT5a-short (S). ${ }^{29}$ In colorectal cancer cell lines and specimens, the expression level of WNT5a-Short (S) subtype transcript was higher, while that of WNT5a-Long (L) subtype transcript was lower. The high expression of WNT5a-S mRNA subtype and the low expression of WNT5a-L mRNA subtype were positively correlated with the tumor grade of patients with colorectal cancer. ${ }^{45-47}$

\section{WNT5a in the Process of Occurrence and Development of CRC}

There is no hard evidence to prove the exact function of WNT5a. Some studies suggest that WNT5a is a tumor suppressor, while others suggest the opposite. During the development of colorectal cancer, WNT5a showed different functions in different signal transduction pathways. Next, we will review the research progress of WNT5a, 
including its role in the promotion, inhibition, prognosis, and treatment of colorectal cancer.

\section{WNT5a in CRC Promotion}

A large number of signal pathways that promote the development of CRC are accompanied with the downregulation and upregulation of WNT5a (Figure 3). Tumor microenvironment (TMA) is closely related with tumor progress. ${ }^{59,60}$ As one of most immune cells, tumor-associated macrophage (TAM) secrets abundant mediators to inhibit antitumor immune responses, stimulates blood vessel formation and finally enhances the proliferation, invasion, intravasation and dissemination of cancer cells. ${ }^{61-63}$ The level of WNT5a+/CD68+/CD68+TAMS, belonging to M2 TAM subtype, was negatively correlated with the prognosis of the patients. WNT5a induces TAM to secrete IL-10 through ERK1/2 and STAT3 pathways. IL-10 can be used as an autocrine cytokine to induce M2 polarization of TAM. IL-
10 neutralizing antibodies can completely prevent this polarization process. M2 TAMs induced by WNT5a play a positive role in the occurrence and development of tumor. Knocking out WNT5a in TAMs can significantly inhibit this function of TAMS. ${ }^{64}$

Forkhead box transcription factor M1 (FOXM1) is a proliferation-associated transcription factor regulated by dimethylation on H3 lysine 79 (H3K79me2), which takes part in tumor progress through regulating the transcription of its target genes. ${ }^{65}$ In colon cancer, H3K79me2-FOXM1 inhibits antitumor responses including BMDC maturation, cytokine secretion and T-cell activation. At the same time, FOXM1 upregulates the transcription of WNT5a, Exogenous WNT5a expression can inhibit FOXM1 and the modification of H3K79ME2, which abrogated BMDC maturation phenotypes. Overall, upregulation of FOXM1 via $\mathrm{H} 3 \mathrm{~K} 79 \mathrm{me} 2$ inhibits maturation phenotypes and function of BMDCs through the WNT5a signaling pathway. ${ }^{66}$

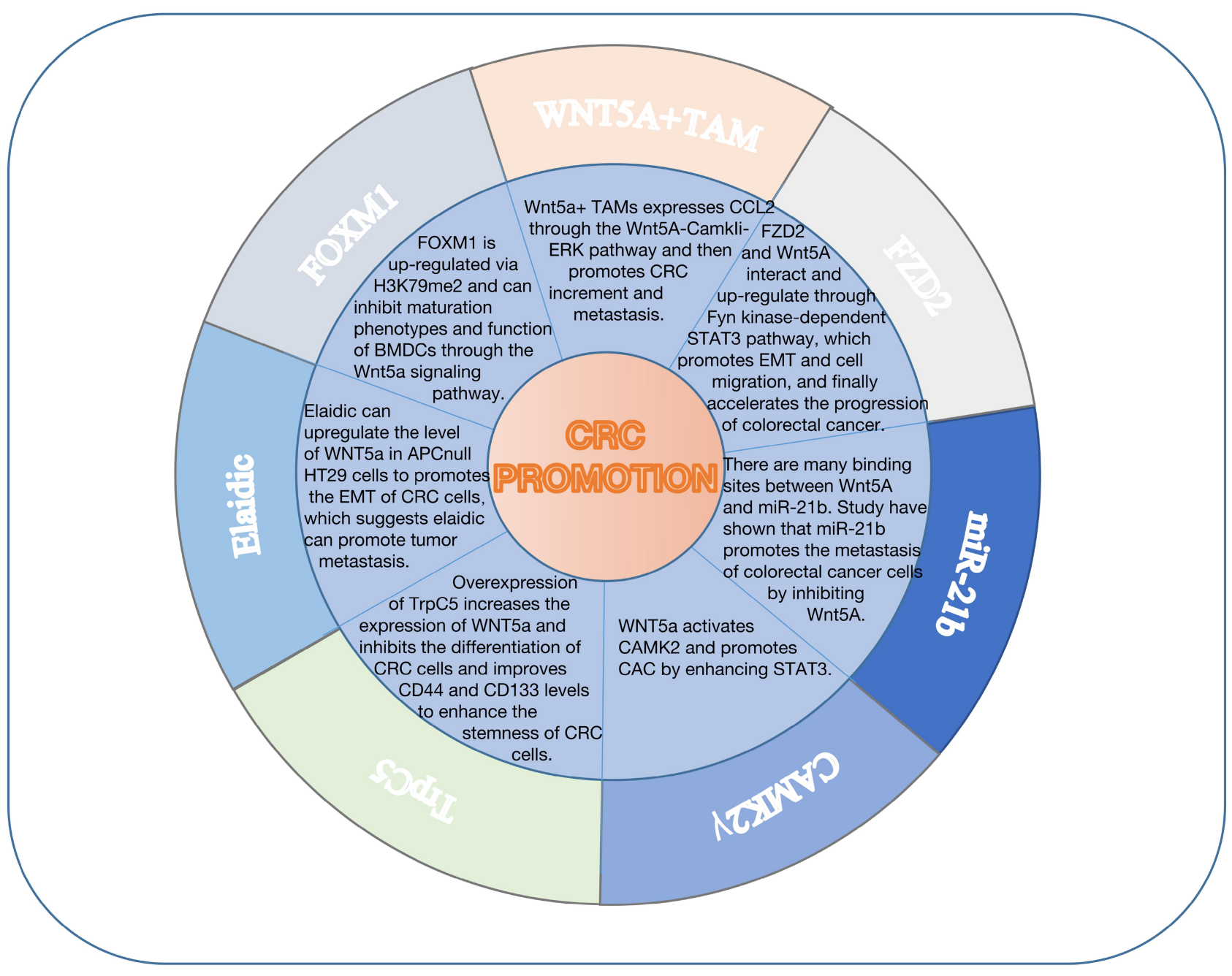

Figure 3 WNT5a promotes the occurrence and development of colorectal cancer through multiple signal transduction pathways. 
Trans fatty acids (TFA) is one of cardiovascular disease risk factors and has been reported to have a possible CRC risk. ${ }^{67}$ Elaidic (EA), a kind of TFA, can upregulate the level of WNT5a in APCnull HT29 cells, which promotes the EMT of CRC cells, suggesting its ability to promote tumor metastasis. ${ }^{68}$ MiR-21b is controversial in CRC, research reveals that miR-21b is negative related with the prognosis of CRC patient. ${ }^{69}$ When inflammatory bowel disease-associated cancer intensified, the level of miR$21 \mathrm{~b}$ in tissue and serum upregulated sharply. ${ }^{70}$ At the same time, some research reveal that the expression of miR-21b was lower in CRC tissue than in normal tissue. ${ }^{71}$ WNT5a has many highly conserved binding sites for miR-21b, by which miR-21b directly suppresses the expression of WNT5a in CRC cell line. ${ }^{72}$ Some reports have revealed that WNT5a can repress canonical WNT/ $\beta$ catenin-dependent singling pathway, which promotes EMT. $^{73}$ Therefore, Fan's ${ }^{71}$ study shows that miR-21b promotes the metastasis of CRC cells by suppressing WNT5a.

Calcium/calmodulin-dependent protein kinase II gamma (CAMK2 $\gamma$ ) is a kind of serine and threonine kinases and is a downstream molecule of colitis-induced WNT5a signaling, which belongs to calcium/calmodulindependent protein kinase II family. ${ }^{74,75}$ Researchhave revealed that many inflammation, caused by variety factors need the participation of CAMK2 $\gamma .{ }^{76-78} \mathrm{Ma}^{\prime}{ }^{74}$ study has shown that the overexpression of constitutive CAMK $2 \gamma$ located in colon tissue can prevent enteritis and intestinal injury induced by sodium dextran sulfate in mice, thus protecting intestinal epithelial cells and promoting their proliferation. Further studies have shown that CAMK2 $\gamma$ can be activated by WNT5a in colitis-associated colorectal cancer and promote the occurrence of colitis-associated colorectal cancer by enhancing STAT3.

FZD2 is overexpressed in poorly differentiated mesenchymal cancer, which can promote EMT and stimulate cells migration. ${ }^{79}$ In CRC, FZD2 and WNT5a interact and up-regulate each other and in turn facilitate EMT and cells migration and accelerate the process of CRC finally. The whole process is done through Fyn kinase-dependent STAT3 pathway. The mechanism is that tyrosine phosphorylation of FZD2 is not recognized by kinases at the Tyr552 site, and then this phosphorylation promotes the binding of FZD2 to the SH2 region of Fyn, which activates tyrosine phosphorylation at Tyr705 and functions as the STAT3 pathway, resulting in the occurrence of EMT and cancer. ${ }^{80}$
Tumor microenvironment (TME) includes tumor cells, immune cells, tumor-associated fibroblasts and extracellular matrix, which is closely related to the occurrence and development of tumors. ${ }^{81}$ The largest number of immune cells are macrophages, called tumor-associated macrophages (TAM), which are divided into classical activated macrophages (M1 phenotype) and alternately activated macrophages (M2 phenotype). ${ }^{82-84}$ Studies have shown that WNT5a is mainly expressed in M2-like TAM of TME. WNT5a+TAMS can significantly promote the proliferation and metastasis of colorectal cancer, but WNT5a does not directly affect this process, but through promoting TAM to express CCL2. Further studies have shown that the CCL2 expression of TAMS depends on the WNT5a-CaMKII-ERK pathway. ${ }^{85}$

Transient receptor potential (Trp) channel is a type of ion channel located in the plasma membrane, TrpC5 is a subtype of TrpC, which can form a receptor-activated non-selective $\mathrm{Ca} 2+$ channel. $^{86}$ In the CRC cells line, $\mathrm{TrpC} 5$ is overexpressed, causing a robust $[\mathrm{Ca} 2+] \mathrm{i}$ rise and a higher expression of WNT5a, by which TrpC5 can suppress the differentiation of CRC cells. Besides, the overexpression of $\operatorname{TrpC} 5$ can increase the level of CD44 and CD133 throughWNT5a signal pathway and in turn enhance the stemness of CRC cells. All these promote the development of CRC. ${ }^{87}$

Elvira's research elucidated that the improvement of WNT5a expression promoted the invasion and migration in human CRC. WNT5a knockdown in human CRC had a function of inhibiting directional migration and weakening the formation of focal adhesion site. But when inducing the expression of WNT5a in the intestinal tumor of Apc1638N mice, there is no obvious carcinogenic effect. ${ }^{45}$ To sum up, we have plotted Figure 3 and Table 1, so it is not difficult to see that WNT5a plays an important role in the promotion of CRC.

\section{WNT5a in CRC Inhibition}

In addition to the promotion of colorectal cancer, the role of WNT5a in the inhibition of colorectal cancer has also attracted our attention. Receptor tyrosine kinase(RTK) regulates a variety of diseases, including cancer, through its unique role in cell proliferation, apoptosis, differentiation, and migration. ${ }^{88,89}$ Receptor tyrosine kinase-like orphan receptor 2(ROR2) is a member of RTKs, which can induce the cancer cell cycle arrest and apoptosis and further antagonize the EMT and tumor cells stemness via repressing the $\beta$-catenin and AKT signaling. In return, 
Table I WNT5a Promotes the Occurrence and Development of Colorectal Cancer Through Multiple Signal Transduction Pathways

\begin{tabular}{|c|c|c|c|}
\hline Factors & Mechanism & Function & Reference \\
\hline $\begin{array}{l}\text { WNT5A } \\
+ \text { TAM }\end{array}$ & $\begin{array}{l}\text { WNT5A+TAMS expresses CCL2 through WNT5A-CaMKII-ERK pathway to promote the } \\
\text { proliferation and metastasis of CRC. }\end{array}$ & CRC Promotion & [85] \\
\hline Elaidic & $\begin{array}{l}\text { Elaidic can up-regulate the expression of Wnt5A in APCnull HT29 cells, which can promote the } \\
\text { EMT, of colorectal cancer cells, suggesting that it has the ability to promote tumor metastasis. }\end{array}$ & CRC Promotion & [68] \\
\hline MiR-2Ib & $\begin{array}{l}\text { There are many high binding sites between Wnt5A and Mir- } 2 \mathrm{lb} \text {. Studies have shown that Mir- } 2 \mathrm{Ib} \\
\text { promotes the metastasis of colorectal cancer cells by inhibiting Wnt5A. }\end{array}$ & CRC Promotion & [70] \\
\hline CAMK $2 \gamma$ & WNT5a activates CAMK2 and promotes CAC by enhancing STAT3. & CRC Promotion & [74] \\
\hline FZD2 & $\begin{array}{l}\text { FZD2 and Wnt5A interact and up-regulate through Fyn kinase-dependent STAT3 pathway, which } \\
\text { promotes EMT and cell migration, and finally accelerates the process of colorectal cancer. }\end{array}$ & CRC Promotion & [80] \\
\hline FOXMI & $\begin{array}{l}\text { Up-regulation of FOXMI by } \mathrm{H} 3 \mathrm{~K} 79 \mathrm{me} 2 \text { can inhibit the mature phenotype and function of BMDCs } \\
\text { through Wnt5a signal pathway. }\end{array}$ & CRC Promotion & [66] \\
\hline TrpC5 & $\begin{array}{l}\text { The overexpression of TRPC } 5 \text { increases the expression of Wnt5A, inhibits the differentiation of } \\
\text { colorectal cancer cells, and increases the expression levels of CD } 44 \text { and CDI33, thus enhancing the } \\
\text { dryness of colorectal cancer cells. }\end{array}$ & CRC Promotion & [87] \\
\hline
\end{tabular}

ROR2 is considered as a tumor suppressor in variety cancers include CRC. Unfortunately, ROR2 was usually methylated in the progress of tumors, which promotes the development of tumor. ${ }^{25,90}$ Abundant past research has described the relationship between WNT5a and ROR2 that ROR2 is the receptor or coreceptor of WNT5a and the activity of ROR2 is directly regulated by WNT5a. ${ }^{91,92}$ But an interesting conclusion was put forward in $\mathrm{Li}^{9}{ }^{90}$ research, there is no obvious correlation between the expression of WNT5a and ROR2, and the tumor inhibition function of ROR2 is independent of WNT5a.

Brucine is a kind of natural plant alkaloids, which has been proved to own abundant pharmacological effects include cytotoxic, anticellular proliferation, antiangiogenesis and antitumor. It is separated from dry seeds of Strychnos nux-vomica L. (Loganiaceae). ${ }^{93}$ In the lovo cells, brucine has an obvious inhibitory effect through repressing $\mathrm{WNT} / \beta$-catenin pathway and further represses the level of MMPs, the downstream molecules of WNT/ $\beta$ catenin pathway. During this process, brucine down regulates the level of WNT5a. ${ }^{94}$

Daple is a guanine nucleotide exchange factor (GEF) for the $\mathrm{G}$ protein $\mathrm{Gi}$, which can directly bind to the FZD and the WNT/FZD mediator Dishevelled (Dvl) to stimulate and enhance noncanonical WNT pathway. ${ }^{95}$ 15-PGDH is a tumor suppressor which plays a key role in catabolism of prostaglandin E2. Prostaglandin E2 can amplify inflammation and tumor growth in the colon tumor microenvironment. 15-PGDH decreased significantly in patients with colorectal cancer. WNT5a can up regulate the expression of $15-\mathrm{PGDH}$ via active JNK, which is the downstream signal of WNT5a. This progress of activation actives AP-1, which is a transcription factor binding to the promoter of 15-PGDH. It is verified that canonical WNT signaling down-regulates 15-PGDH and WNT5a can weaken this down-regulation effect, which suggests that WNT5a can regulate 15-PGDH by this inhibition. Overall, WNT5a can inhibit CRC by upregulating the expression of 15 -PGDH. ${ }^{96}$

Fatty acid synthase (FASN) is a key metabolic enzyme in the terminal catalytic step of fatty acid synthesis, which is active in a variety of tumors. ${ }^{97}$ Wang's ${ }^{98}$ study shown that Fasn was upregulated in CRC, which contributed to a more advanced clinical phenotypes and lymphatic and distant metastasis. Knocking down Fasn can attenuate WNT signaling pathway through down- regulating the expression of WNT5a, which at least partly inhibited metastasis.

In mammal, polycomb repression complex-2 (PRC2) is one kind of highly conserved histone methyltransferase, taking part in the regulation of epigenetic. ${ }^{99}$ Enhancer of zeste Homolog 2 (EZH2) is a catalytic submit of PRC2. ${ }^{100}$ In SW480 colon cancer cells line, EZH2 is enriched at the promoter region of WNT5a, and in turn upregulates the level of Histone 3 lysine 27 trimethylation (H3K27me3). 
This process silences the expression of WNT5a, thus inhibitsthe EMT induced by TGF- $\beta$, and finally indicates its potential ability to inhibit tumor metastasis. ${ }^{101}$

MiR-335 can inhibit the EMT and the growth of CRC HCT116 cell line by targeting Twist1. At the same time, miR-335 can suppress WNT5a. ${ }^{102}$ The R-spondins (RSPO), members of a super family of thrombospondin type 1 repeat (TSR-1)-containing proteins, usually acts as a WNT/catenin signal agonist. ${ }^{103}$ Research have shown that RSPO2 is downregulated in CRC, suggesting it's function of antitumor. ${ }^{104}$ Further study of Dong ${ }^{105}$ demonstrated that the binding of WNT5a and FZD7 drives the noncanonical WNT signaling pathway, however RSPO2 can break this bind and the physical interaction of RSPO2 and FZD7 suppresses the noncanonical WNT signaling pathway, and in turn reduces EMT, by which the metastasis of CRC is prevent.

Hyperparathyroidism 2 (HRPT2) can encode a protein called parafibromin, the mutation of which contributes to hyperparathyroidism-jaw tumor syndrome and parathyroid cancers. ${ }^{106}$ The existing research shows that the expression of parafibromin is negatively related to the invasive ability of colorectal cancer. ${ }^{107}$ For Shen et al's research, the overexpression of parafibromin had an ability to repress ovarian cancer via down regulating WNT5a, VEGF, and MMP-9. ${ }^{108}$

Receptor tyrosine kinase-like orphan receptor is a ROR family of receptor tyrosine kinase, research shown that it's a receptor or coreceptor of WNT5a. ${ }^{109}$ Lee et al's ${ }^{110}$ researchshown that the phosphorylation of RORa in serine residue 35 can resist the $\mathrm{WNT} / \beta$-catenin-dependent signaling pathway. The specific mechanisms were as follows: the overexpression of WNT5a can increase the level of Protein Kinase C a (PKCa), the WNT5a-mediated PKCa can stimulate a phosphorylation on the serine residue 35 of RORa, this phosphorylation can promote the $\beta$-catenin bond with the serine 35 of RORa, and possibly induce a competition between RORa and other coactivators for $\beta$ catenin. Further, this combination repressed the expression oftarget gene of the WNT/ $\beta$-catenin-dependent signaling pathway and in turn reduced this pathway.

Cheng's research ${ }^{48}$ came to the opposite conclusion, that WNT5a can inhibit EMT by down-regulating Twist and ZEB1, which are considered to be the key regulators of EMT, thus weakening the ability of the tumor movement and invasion. Coincidentally, Ying's ${ }^{47}$ study has also shown that WNT5a can weaken the canonical WNT pathway by inhibiting $\beta$-catenin and its receptors, thus showing tumor inhibitory activity.

From the above studies, it can be seen that WNT5a also plays an important role in the inhibition of colorectal cancer. We also drew Figure 4 and Table 2 to visually understand the role of WNT5a in CRC suppression.

\section{WNT5a in CRC Therapy}

The therapeutic effect of WNT5a on CRC patients has been demonstrated in many studies. Azoxymethane (AOM) and dextran sodium sulfate (DSS) induce colitis associated CRC (caCRC) via upregulating the level of transforming growth factor $\beta 1$ (TGF- $\beta 1$ ). Then TGF- $\beta 1$ directly forms a complex called Smad and indirect actives NF- $k \beta$, this process can upregulate the level of WNT5a. Then WNT5a treatment actives Snail and initiates transition event, which promotes epithelial mesenchymal transition (EMT) with downregulation of E-card and up regulation of Vimentin. Shenling Baizhu San (SBS) is a well known traditional Chinese medicine (TCM), which has been used to treat gastrointestinal disorder for 9hundred years ago. The progress described above could be alleviated by the TCM. SBS can decrease the level of TGF- $\beta 1$, in turn partly stop WNT5a-induced EMT to achieve the function of suppressing caCRC. ${ }^{111}$

Genistein (GEN) increases the level of WNT genes such as WNT5a and SFRP2 in colorectal cancer by demethylating $\mathrm{CpG}$ in the promoter, ${ }^{12,113}$ which inhibits canonical WNT/ $\beta$-catenin-independent signaling pathway. ${ }^{114}$ At the same time, azoxymethane (AOM) is a chemical carcinogen, which can induce the expression of WNT5a. In the carcinogen-injected rats by AOM, dietary GEN can increase the methylation of specific $\mathrm{CpG}$-rich region within WNT5a after AOM processing. At the same time, dietary GEN can repress binding of the pol 11 at the promoter of WNT5a, which can be enhance in the postAOM period. Dietary GEN can reduce the acetylation of lysine residues of histone $\mathrm{H} 3$ and suppress ethylation of lysine 9 and phosphorylation of Serine 10 of histone $\mathrm{H} 3$ at promoters of WNT5a in the post-AOM period through increasing the level of nuclear HDAC3. All of the above mechanisms make dietary GEN realize this function that maintain a normal WNT signaling level in the colon epithelium of carcinogen-injected rats, suggesting a potential therapeutic pathway. ${ }^{115}$

Butyrate is a fiber fermentation product in colon. Existing research results had shown that butyrate can induce apoptosis of colon cancer cells through acting as 


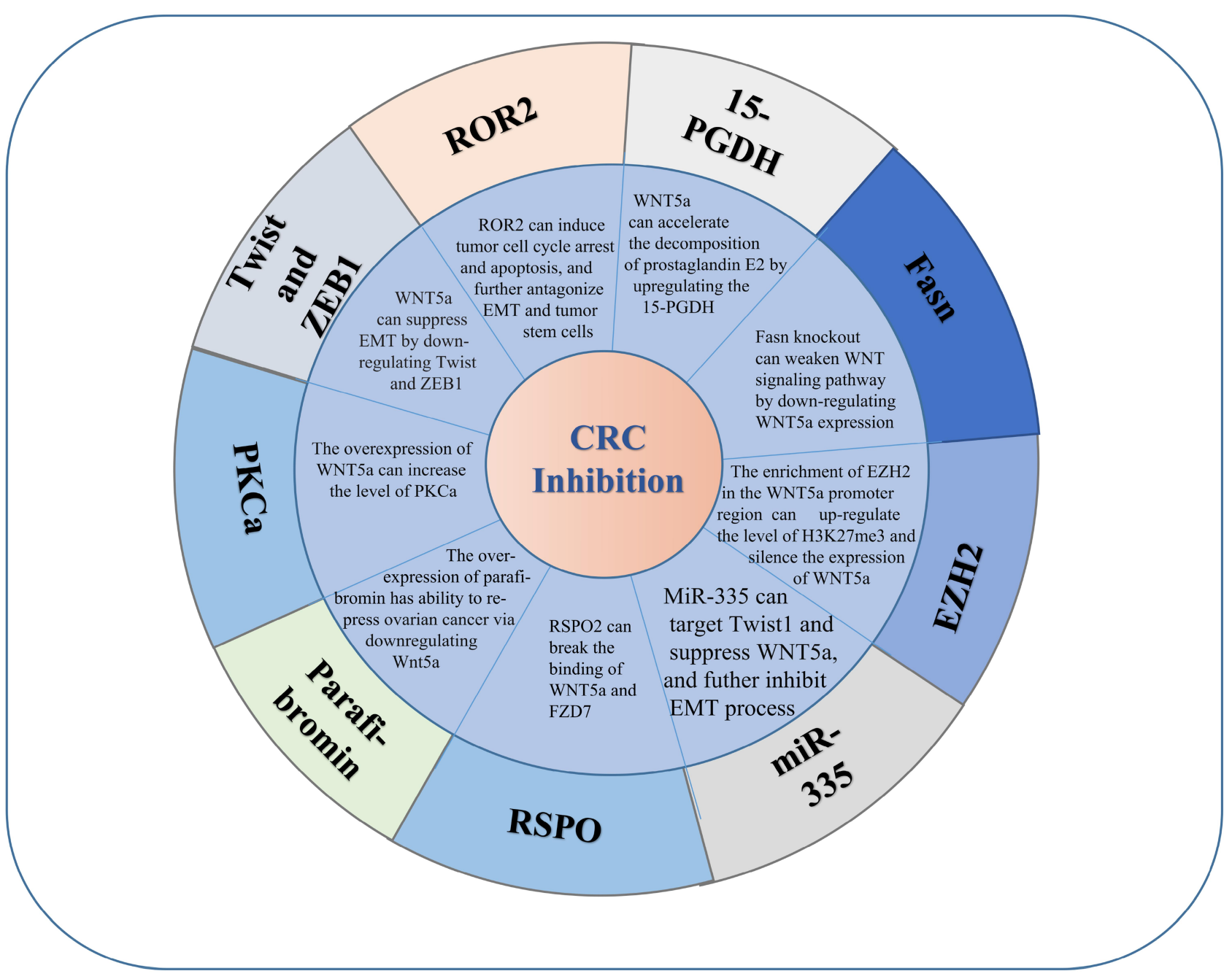

Figure 4 WNT5a inhibits the occurrence and development of colorectal cancer through multiple signal transduction pathways.

a histone deacetylase inhibitor (HDACi) in vitro and in turn resists cancers and the canonical WNT pathway can enhance this apoptosis. ${ }^{116,117}$ Prolonged exposure to butyrate can cause colorectal cancer cells to resist the above apoptosis and induce resistance to a variety of HDACis. Further research have shown that prolonged exposure to butyrate upregulated the expression of WNT5a and WNT11 with the upregulation of expression of WNT5a receptor ROR2, by which the AKT/PKB signaling pathway was activated and noncanonical WNT pathway was enhanced. ${ }^{116}$ For the past study, noncanonical WNT pathway could reduce the canonical WNT pathway, whereby the apoptosis of butyrate was resisted and eventually the HDACi-resistance was induced. ${ }^{118}$

Pomegranate tree was used for treatment of variety of disease including sore throat, inflammation, and rheumatism in Greco-Arab medicine for centuries. It was often used as a cure for cancer in the Middle East. ${ }^{19-121} 1$, 2-dimethylhydrazine (DMH), a chemical carcinogen, is used to induced $\mathrm{CRC}$ rats. In those rats, the level of WNT5a is obviously raised. Pomegranate tree extract (PTE) can fix this abnormal expression of WNT5a and further suppress CRC process. ${ }^{122}$

Fox5 is a hexapeptide WNT5a agonist. As a recombinant agonist of WNT5a, Fox5 can trigger rich signal events and functional responses. Compared with WNT5a, Fox5 is a much simpler molecule that can be systematically administered and reach tumor tissue. ${ }^{123,124}$ For Janina's research, Fox 5 can cut back the number of colonic cancer stem cells (CSCs) in a xenograft mouse model of human colonic cancer probably by target suppression of three different targets include $\beta$-catenin signaling, COX2 and 15-PGDH, which can promote colonic CSCs, and in turn repressed colonic CSCs. ${ }^{125}$ 
Table 2 WNT5a Inhibits the Occurrence and Development of Colorectal Cancer Through Multiple Signal Transduction Pathways

\begin{tabular}{|c|c|c|c|}
\hline Factors & Mechanism & Function & Reference \\
\hline ROR2 & $\begin{array}{l}\text { ROR2 is the receptor or coreceptor of } \mathrm{Wnt} 5 \mathrm{~A} \text { and is regulated by } \mathrm{Wnt} 5 \mathrm{~A} \text {. It can induce tumor } \\
\text { cell cycle arrest and apoptosis by inhibiting catenin and AKT signal pathway, and then antagonize } \\
\text { EMT and tumor stem cells. }\end{array}$ & CRC inhibition & {$[25,90]$} \\
\hline I5-PGDH & $\begin{array}{l}\text { WNT5A can promote the decomposition of prostaglandin E2 by up-regulating I5-PGDH, thus } \\
\text { reducing inflammation and tumor growth in tumor microenvironment, and ultimately inhibiting } \\
\text { colorectal cancer. }\end{array}$ & CRC inhibition & [96] \\
\hline Fasn & $\begin{array}{l}\text { Fasn knockout can weaken WNT signaling pathway by down-regulating WNT5a expression, at } \\
\text { least partially inhibiting metastasis. }\end{array}$ & CRC inhibition & [98] \\
\hline $\mathrm{EZH} 2$ & $\begin{array}{l}\text { The enrichment of EZH } 2 \text { in the Wnt5A promoter region further up-regulated the expression of } \\
\mathrm{H} 3 \mathrm{~K} 27 \mathrm{me} 3 \text { and inhibited the expression of } \mathrm{Wnt} 5 \mathrm{~A} \text {, thus inhibiting the transformation of epithelial } \\
\text { endothelial cells induced by transforming growth factor- } \beta \text { and inhibiting tumor metastasis. }\end{array}$ & CRC inhibition & {$[101]$} \\
\hline miR-335 & $\begin{array}{l}\text { MiR-335 can target Twistl and suppress WNT5a, and in turn inhibit EMT process and the growth } \\
\text { of CRC HCTII6 cell line. }\end{array}$ & CRC inhibition & {$[102]$} \\
\hline RSPO & $\begin{array}{l}\text { RSPO2 can destroy the combination of Wnt5A and FZD7, inhibit the irregular Wnt signal pathway } \\
\text { through the physical interaction between RSPO2 and FZD7, and then reduce EMT, thus preventing } \\
\text { the metastasis of colorectal cancer. }\end{array}$ & CRC inhibition & [105] \\
\hline Parafibromin & $\begin{array}{l}\text { The overexpression of parafibromin has ability to repress ovarian cancer via down-regulating } \\
\text { Wnt5a, VEGF, and MMP-9. }\end{array}$ & CRC inhibition & {$[106,107]$} \\
\hline $\mathrm{PKC} \alpha$ & $\begin{array}{l}\text { The overexpression of WNT5a can increase the level of PKC } \alpha \text {, and in turn stimulate } \\
\text { a phosphorylation on the serine residue } 35 \text { of RORa and then promote the } \beta \text {-catenin bond with } \\
\text { the serine } 35 \text { of RORa, this combination represes the expression of target gene of the WNT/ } \beta- \\
\text { catenin-dependent signaling pathway and in turn reduces this pathway. }\end{array}$ & CRC inhibition & {$[110]$} \\
\hline $\begin{array}{l}\text { Twist and } \\
\text { ZEBI }\end{array}$ & $\begin{array}{l}\text { WNT5A inhibits EMT by down-regulating the key regulatory factors Twist and ZEBI of EMT, thus } \\
\text { weakening the motor and invasive ability of tumors. }\end{array}$ & CRC inhibition & [48] \\
\hline
\end{tabular}

Rimonabant (SR114617), a inverse agonist of cannabinoid receptor 1 (CB1), exhibits a strong anti-tumor effect. $^{126-128}$ In HCT cells, 8 hours of treatment of rimonabant can increase the level of protein of both WNT5a and ROR2 and induce the activation of CaMK2, by which rimonabant promotes the noncanonical WNT pathway and suppress the canonical WNT pathway. ${ }^{129}$

Previous studies have found that 5-fluorouracil chemotherapy for pancreatic cancer is interfered with WNT5a levels. ${ }^{130}$ Jiang's $^{131}$ research put forward that the level of WNT5a promoter methylation was positively related with the curative effect of 5-FU in CRC. The antitumor function of 5-FU was repressed by the high WNT5a level in the hypermethylated cells line which include HCT116 and SW620 cells while enhanced by the down-regulated WNT5a in the demethylated cells line include Lovo and SW480 cells. Above suggests that the high WNT5a methylation status is associated with better drug response and longer progression-free survival.

Recently meta analysis pointed out the association between incidence of CRC and serum level of calcidiol [25-dihydroxyvitamin D3, (25-D3)], which play its antitumorigenic function by regulating the deregulated signaling pathways. ${ }^{132,133}$ In Charlotte's ${ }^{134}$ study, the levels of WNT5a and ROR2 in the normal colon of mice fed with high vitamin $\mathrm{D}$ diet were increased, while the levels of $\beta$ catenin and TCF-4 were down-regulated, which suggested the great power of 1.25-D3 in inhibiting WNT signaling, even in nonmalignant cells, and further emphasizes its importance in anti-tumorigenesis of colorectal tissue and preventing the progression of early colorectal cancer.

Simvastatin is a kind of 3-hydroxy-3-methylglutarylCoA (HMG-CoA) reductase inhibitor, which inhibits breast cancer, lung cancer, colon cancer and other tumors through many ways. ${ }^{135-138}$ Lu's $^{139}$ study 
illustrated that simvastatin can suppress the mevalonate pathway by upregulating the expression of Kruppel-like factor 2 (KLF2) and p21(WAF1/CIP1) in colon cancer with P53 mutation. This progress has been proved to act as an antitumor pathway. Further research have shown that overexpression KLF2 can induce the level of p21 (WAF1/CIP1). In p53 mutation, the expression of WNT5a is significantly increased, and KLF2-mediated WNT5a inhibition may play a key role in the closure of WNT signal and the anti-metastatic effect of simvastatin.

Ciappio's ${ }^{140}$ research shown us that in the APC1638N mouse offspring, the level of WNT5a, Apc, Sfrp1, and Wif1, all of which was the inhibitor of canonical WNT pathway, was positive related with their mother' intake of maternal B vitamin. Further research shown that the mother's intake of maternal B vitamin could suppress the incidence of intestinal tumorigenesis in their offspring.

\section{WNT5a in CRC Prognosis}

Some studies have pointed out the role of WNT5a in the prognosis of CRC.

WNT5a and WNT5B ligand and their cognate receptor Frizzled2, an oncogene, which promotes last-stage metastasis, have an obvious upregulation in CRC. ${ }^{141}$ It is well known that STAT3 mediates cytokine signal transduction and induces a variety of inflammatory responses. ${ }^{142}$ Balanis's ${ }^{143}$ research showed that STAT3 promoted EMT via changing the transcription factor such as Zed1. But a novel mechanism of STAT activation was found in multiple tumor cells expressing FZD2-WNT5a, which regulated EMT, cell migration and invasion: Fyn could associate with FZD2-Tyr552 via it's SH2 domain, binds to ligand, and phosphorylate STAT3, which converted epithelial morphology to a migratory mesenchymal one. FZD2 also has an influence on other factors regulating EMT such as Tgfb2 and Bmp2, which suggests that it is a key factor during EMT progress. ${ }^{80}$ Overall, the gene markers regulated by the FZD2/WNT5a pathway seem to have a strong predictive value for colorectal cancer metastasis and overall patient survival.

Somatic methylation of the promoter of MLH1 causes majority of sporadic CRC with microsatellite instability (MSI) and the $\mathrm{CpG}$ island methylator phenotype (CIMP). ${ }^{144}$ The CRC tumor with MSI often exhibited a favorable outcome, whereas the CRC tumor with CIMP shown a complex outcome associated with the status of MSI and BRAF V600E. BRAF V600E is a substitute marker of high CIMP and is a dependent prognostic factor of CRC tumor, which is associated with a poor outcome. Research has put forward that we can forecast the outcome of CRC tumor by determining the status of MSI/CIMP/BRAF V600E. ${ }^{145-150}$ Compared to in the microsatellite stability (MSS), WNT5a methylation is much more common in MSI. This relationship is independent of the patient's age, sex and other influencing factors. Meanwhile, the WNT5a methylation is associated with the methylation of MLH1, a primary cause of sporadic MSI tumor. The WNT5a methylation is strongly related to the BRAF V600E mutation. The strong and independent relationship of WNT5a methylation and MSI/BRAF V600E suggested that this methylation may be a prognostic marker associated with a favorable outcome. $^{151}$ In fact, a large number of previous studies have shown that WNT5a has a discordant function in CRC. Related research points out that the early expression of WNT5a can inhibit the process of CRC by suppressing the canonical WNT pathway, while the late expression of WNT5a can promote the CRC cells invasion by noncanonical WNT pathway. ${ }^{152}$

The expression of WNT5a is downregulated in 50\% of dukes B tumor. Compared to the patient with WNT5anegative primary tumor, the median survival of those with WNT5a-positive primary tumor is higher obviously. More in-depth research data show that when comparing SW480 cells line, which does not express WNT5a protein and poorly differentiated, and $\mathrm{CACO} 2$ colon cancer cells line, which express WNT5a protein and properly differentiated, the research show that the addition of recombinant/ purified WNT5a obviously repressed the migration force of SW480 cells, when the same treatment was done to $\mathrm{CACO} 2$ colon cancer cells line, the migration characteristic did not exhibit obviously change. In conclusion, the level of WNT5a is positive-related with the prognosis of patients with primary dukes B colon tumor. ${ }^{153}$

From existing research, the hypermethylation of WNT5a is related to the poor prognosis and disease recurrence of Resected Stage III Proximal Colon Cancer. ${ }^{154,155}$ Kamposioras et al's ${ }^{156}$ study also prompts us that WNT5a has a potential to act as a prognostic factor in surgicallytreated colorectal cancer.

\section{Conclusion}

WNT5a signaling pathway plays an important regulatory role in the occurrence and development of tumors. Therefore, WNT5a signal has been a hotspot in oncology 
research. This paper reviews the recent progress of WNT5a in the occurrence, development, and treatment of colorectal cancer, and discusses the role of WNT5a in the promotion/inhibition/prognosis/treatment of colorectal cancer. Through the discussion of this topic, we hope to deepen the understanding of WNT5a in the occurrence and development of colorectal cancer, and arouse the interest of researchers in the design of new treatment strategies for colorectal cancer based on WNT5a.

\section{Disclosure}

The authors declare that they have no competing interests.

\section{References}

1. Haggar FA, Boushey RP. Colorectal cancer epidemiology: incidence, mortality, survival, and risk factors. Clin Colon Rectal Surg. 2009;22(04):191-197. doi:10.1055/s-0029-1242458

2. Grizzi F, Bianchi P, Malesci A, Laghi L. Prognostic value of innate and adaptive immunity in colorectal cancer. World J Gastroenterol. 2013;19:174-184. doi:10.3748/wjg.v19.i2.174

3. Johnson CM, Wei C, Ensor JE, et al. Meta-analyses of colorectal cancer risk factors. Cancer Causes Control. 2013;24 (6):1207-1222. doi:10.1007/s10552-013-0201-5

4. Mengual-Ballester M, Pellicer-Franco E, Valero-Navarro G, Soria-Aledo V, Garcia-Marin JA, Aguayo-Albasini JL. Increased survival and decreased recurrence in colorectal cancer patients diagnosed in a screening programme. Cancer Epidemiol. 2016;43:70-75. doi:10.1016/j.canep.2016.06.003

5. Hubner J, Lewin P, Pritzkuleit R, Eisemann N, Maier W, Katalinic A. Colorectal cancer screening by colonoscopy and trends in disease-specific mortality: a population-based ecological study of 358 German districts. Int J Colorectal Dis. 2019;34 (4):599-605. doi:10.1007/s00384-018-03226-6

6. Schweiger MR, Hussong M, Rohr C, Lehrach H. Genomics and epigenomics of colorectal cancer. Wiley Interdiscip Rev Syst Biol Med. 2013;5:205-219.

7. Guinney J, Dienstmann R, Wang X, et al. The consensus molecular subtypes of colorectal cancer. Nat Med. 2015;21:1350-1356.

8. Jasperson KW, Tuohy TM, Neklason DW, Burt RW. Hereditary and familial colon cancer. Gastroenterology. 2010;138:2044-2058.

9. Bodmer WF, Bailey CJ, Bodmer J, et al. Localization of the gene for familial adenomatous polyposis on chromosome 5. Nature. 1987;328:614-616.

10. Cancer Genome Atlas N. Comprehensive molecular characterization of human colon and rectal cancer. Nature. 2012;487:330-337.

11. Nusse R, Varmus HE. WNT genes. Cell. 1992;69(7):1073-1087. doi:10.1016/0092-8674(92)90630-U

12. Kumawat K, Gosens R. WNT-5a: signaling and functions in health and disease. Cell Mol Life Sci. 2016;73(3):567-587. doi:10.1007/s00018-015-2076-y

13. Clark CC, Cohen I, Eichstetter I, et al. Molecular cloning of the human proto-oncogene WNT-5a and mapping of the gene (WNT5a) to chromosome 3p14-p21. Genomics. 1993;18 (2):249-260. doi:10.1006/geno.1993.1463

14. Willert K, Nusse R. WNT proteins. Cold Spring Harb Perspect Biol. 2012;4(9):a007864. doi:10.1101/cshperspect.a007864

15. Wong GT, Gavin BJ, McMahon AP. Differential transformation of mammary epithelial cells by WNT genes. Mol Cell Biol. 1994;14:6278-6286. doi:10.1128/MCB.14.9.6278
16. Shimizu H, Julius MA, Giarre M, Zheng Z, Brown AM, Kitajewski J. Transformation by WNT family proteins correlates with regulation of beta-catenin. Cell Growth Differ. 1997;8 (12):1349-1358.

17. Jiang W, Crossman DK, Mitchell EH, Sohn P, Crowley MR, Serra R. WNT5a inhibits metastasis and alters splicing of Cd44 in breast cancer cells. PLoS One. 2013;8(3):e58329. doi:10.1371/ journal.pone. 0058329

18. Latres E, Chiaur DS, Pagano M. The human F box protein beta-Trcp associates with the Cul1/Skp1 complex and regulates the stability of beta-catenin. Oncogene. 1999;18:849-854. doi:10.1038/sj.onc.1202653

19. Metcalfe C, Mendoza-Topaz C, Mieszczanek J, Bienz M. Stability elements in the LRP6 cytoplasmic tail confer efficient signalling upon DIX-dependent polymerization. J Cell Sci. 2010;123(9):1588-1599. doi:10.1242/jcs.067546

20. Clevers H. WNT/Beta-catenin signaling in development and disease. Cell. 2006;127(3):469-480. doi:10.1016/j.cell.2006.10.018

21. MacDonald BT, Tamai K, He X. WNT/ $\beta$-catenin signaling: components, mechanisms, and diseases. Dev Cell. 2009;17:9-26. doi:10.1016/j.devcel.2009.06.016

22. Tree DRP, Shulman JM, Scott MP, Gubb D, Axelrod JD. Prickle mediates feedback amplification to generate asymmetric planar cell polarity signaling. Cell. 2002;109:371-381. doi:10.1016/ S0092-8674(02)00715-8

23. Habas R, Kato Y, He X. WNT/frizzled activation of Rho regulates vertebrate gastrulation and requires a novel formin homology protein Daam1. Cell. 2001;107(7):843-854. doi:10.1016/S00928674(01)00614-6

24. Kikuchi A, Yamamoto H, Sato A, Matsumoto S. New insights into the mechanism of WNT signaling pathway activation. Int Rev Cell Mol Biol. 2011;291:21-71.

25. Gao B, Song H, Bishop K, et al. WNT signaling gradients establish planar cell polarity by inducing Vangl2 phosphorylation through Ror2. Dev Cell. 2011;20(2):163-176. doi:10.1016/j. devcel.2011.01.001

26. Gao C, Chen Y. Dishevelled: the hub of WNT signaling. Cell Signal. 2010;22(5):717-727. doi:10.1016/j.cellsig.2009.11.021

27. Sheldahl LC, Slusarski DC, Pandur P, Miller JR, Kuhl M, Moon RT. Dishevelled activates Ca2+ flux, PKC, and CamKII in vertebrate embryos. $J$ Cell Biol. 2003;161(4):769-777. doi:10.1083/jcb.200211094

28. Albuquerque C, Baltazar C, Filipe B, et al. Colorectal cancers show distinct mutation spectra in members of the canonical WNT signaling pathway according to their anatomical location and type of genetic instability. Genes Chromosomes Cancer. 2010;49 (8):746-759. doi:10.1002/gcc.20786

29. Bauer M, Benard J, Gaasterland T, Willert K, Cappellen D. WNT5a encodes two isoforms with distinct functions in cancers. PLoS One. 2013;8:e80526. doi:10.1371/journal. pone. 0080526

30. Danielson KG, Pillarisetti J, Cohen IR, et al. Characterization of the complete genomic structure of the human WNT-5a gene, functional analysis of its promoter, chromosomal mapping, and expression in early human embryogenesis. $J$ Biol Chem. 1995;270:31225-31234. doi:10.1074/jbc.270.52.31225

31. Katula KS, Joyner-Powell NB, Hsu CC, Kuk A. Differential Regulation of the Mouse and Human Wnt5a Alternative Promoters A and B. DNA Cell Biol. 2012;31(11):1585-1597. doi:10.1089/dna.2012.1698

32. Mikels AJ, Nusse R. Purified WNT5a protein activates or inhibits beta-catenin-TCF signaling depending on receptor context. PLoS Biol. 2006;4:e115. doi:10.1371/journal.pbio.0040115

33. Qian D, Jones C, Rzadzinska A, et al. WNT5a functions in planar cell polarity regulation in mice. Dev Biol. 2007;306:121-133. doi:10.1016/j.ydbio.2007.03.011 
34. Endo M, Nishita M, Minami Y. Analysis of WNT/planar cell polarity pathway in cultured cells. Methods Mol Biol. 2012;839:201-214.

35. MacMillan CD, Leong HS, Dales DW, et al. Stage of breast cancer progression influences cellular response to activation of the WNT/planar cell polarity pathway. Sci Rep. 2014. doi:10.1038/srep06315

36. Al-Shawi R, Ashton SV, Underwood C, Simons JP. Expression of the Ror1 and Ror2 receptor tyrosine kinase genes during mouse development. Dev Genes Evol. 2001;211(4):161-171. doi: $10.1007 / \mathrm{s} 004270100140$

37. Klaus A, Birchmeier W. WNT signalling and its impact on development and cancer. Nat Rev Cancer. 2008;8:387-398.

38. Slusarski DC, Yang-Snyder J, Busa WB, Moon RT. Modulation of embryonic intracellular Ca2+ signaling by WNT-5a. Dev Biol. 1997;182(1):114-120. doi:10.1006/dbio.1996.8463

39. Kuhl M, Sheldahl LC, Park M, Miller JR, Moon RT. The WNT/ $\mathrm{Ca} 2+$ pathway: a new vertebrate WNT signaling pathway takes shape. Trends Genet. 2000;16:279-283.

40. Kuhl M, Sheldahl LC, Malbon CC, Moon RT. Ca2+/calmodulindependent protein kinase II is stimulated by WNT and frizzled homologs and promotes ventral cell fates in Xenopus. J Biol Chem. 2000;275(17):12701-12711. doi:10.1074/jbc.275.17.12701

41. Thrasivoulou C, Millar M, Ahmed A. Activation of intracellular calcium by multiple WNT ligands and translocation of $\beta$-catenin into the nucleus: a convergent model of WNT/Ca2 + and WNT/ $\beta$ catenin pathways. J Biol Chem. 2013;288(50):35651-35659. doi:10.1074/jbc.M112.437913

42. Bhatt PM, Malgor R. WNT5a: a player in the pathogenesis of atherosclerosis and other inflammatory disorders. Atherosclerosis. 2014;237(1):155-162. doi:10.1016/j.atherosclerosis.2014.08.027

43. Topol L, Jiang X, Choi H, et al. WNT-5a inhibits the canonical WNT pathway by promoting GSK-3-independent $\beta$-catenin degradation. J Cell Biol. 2003;162(5):899-908. doi:10.1083/ jcb. 200303158

44. McDonald SL, Silver A. The opposing roles of WNT-5a in cancer. $B r J$ Cancer. 2009;101(2):209-214. doi:10.1038/sj. bjc. 6605174

45. Bakker ER, Das AM, Helvensteijn W, et al. WNT5a promotes human colon cancer cell migration and invasion but does not augment intestinal tumorigenesis in Apc1638N mice. Carcinogenesis. 2013;34(11):2629-2638. doi:10.1093/carcin/ bgt 215

46. Huang TC, Lee PT, Wu MH, et al. Distinct roles and differential expression levels of WNT5a mRNA isoforms in colorectal cancer cells. PLoS One. 2017;12:e0181034. doi:10.1371/journal. pone.0181034

47. Ying J, Li H, Yu J, et al. WNT5a exhibits tumor-suppressive activity through antagonizing the WNT/beta-catenin signaling, and is frequently methylated in colorectal cancer. Clin Cancer Res. 2008;14:55-61. doi:10.1158/1078-0432.CCR-07-1644

48. Cheng R, Sun B, Liu Z, et al. WNT5a suppresses colon cancer by inhibiting cell proliferation and epithelial-mesenchymal transition. J Cell Physiol. 2014;229(12):1908-1917. doi:10.1 002/jcp. 24566

49. Qiu Q, Li Y, Fan Z, et al. Gene Expression Analysis of Human Papillomavirus-Associated Colorectal Carcinoma. Biomed Res Int. 2020;2020:5201587. doi:10.1155/2020/5201587

50. Ki DH, Jeung HC, Park $\mathrm{CH}$, et al. Whole genome analysis for liver metastasis gene signatures in colorectal cancer. Int J Cancer. 2007;121(9):2005-2012. doi:10.1002/ijc.22975

51. Barski A, Cuddapah S, Cui K, et al. High-resolution profiling of histone methylations in the human genome. Cell. 2007;129 (4):823-837. doi:10.1016/j.cell.2007.05.009
52. Li Q, Chen H. Silencing of Wnt5a during colon cancer metastasis involves histone modifications. Epigenetics. 2012;7(6):551-558. doi:10.4161/epi.20050

53. Belharazem D, Magdeburg J, Berton AK, et al. Carcinoma of the colon and rectum with deregulation of insulin-like growth factor 2 signaling: clinical and molecular implications. $J$ Gastroenterol. 2016;51(10):971-984. doi:10.1007/s00535-016-1181-5

54. Issa JP. CpG island methylator phenotype in cancer. Nat Rev Cancer. 2004;4(12):988-993. doi:10.1038/nrc1507

55. Galamb O, Kalmar A, Peterfia B, et al. Aberrant DNA methylation of WNT pathway genes in the development and progression of CIMP-negative colorectal cancer. Epigenetics. 2016;11:588-602. doi:10.1080/15592294.2016.1190894

56. MacLeod RJ. Extracellular calcium-sensing receptor/PTH knockout mice colons have increased WNT/beta-catenin signaling, reduced non-canonical WNT signaling, and increased susceptibility to azoxymethane-induced aberrant crypt foci. Lab Invest. 2013;93(5):520-527. doi:10.1038/labinvest.2013.51

57. Holcombe RF, Marsh JL, Waterman ML, Lin F, Milovanovic T, Truong T. Expression of WNT ligands and Frizzled receptors in colonic mucosa and in colon carcinoma. Mol Pathol. 2002;55 (4):220-226. doi:10.1136/mp.55.4.220

58. Wang Z, Chen H. Amino acid limitation induces down-regulation of WNT5a at transcriptional level. Biochem Biophys Res Commun. 2009;378(4):789-794. doi:10.1016/j.bbrc.2008.11.124

59. Quail DF, Joyce JA. Microenvironmental regulation of tumor progression and metastasis. Nat Med. 2013;19(11):1423-1437. doi:10.1038/nm.3394

60. Lopez-Soto A, Gonzalez S, Smyth MJ, Galluzzi L. Control of Metastasis by NK Cells. Cancer Cell. 2017;32:135-154.

61. Jiang Y, Li Y, Zhu B. T-cell exhaustion in the tumor microenvironment. Cell Death Dis. 2015;6:e1792.

62. Noy R, Pollard JW. Tumor-associated macrophages: from mechanisms to therapy. Immunity. 2014;41:49-61.

63. Condeelis J, Pollard JW. Macrophages: obligate partners for tumor cell migration, invasion, and metastasis. Cell. 2006;124:263-266.

64. Liu Q, Yang C, Wang S, et al. WNT5a-induced M2 polarization of tumor-associated macrophages via IL-10 promotes colorectal cancer progression. Cell Commun Signal. 2020;18:51.

65. Halasi M, Gartel AL. FOX(M1) news-it is cancer. Mol Cancer Ther. 2013;12(3):245-254.

66. Zhou Z, Chen H, Xie R, et al. Epigenetically modulated FOXM1 suppresses dendritic cell maturation in pancreatic cancer and colon cancer. Mol Oncol. 2019;13:873-893.

67. Valenzuela A, Morgado N. Trans fatty acid isomers in human health and in the food industry. Biol Res. 1999;32:273-287.

68. Fujii K, Luo Y, Fujiwara-Tani R, et al. Pro-metastatic intracellular signaling of the elaidic trans fatty acid. Int J Oncol. 2017;50:85-92.

69. Hsu CM, Lin PM, Wang YM, Chen ZJ, Lin SF, Yang MY. Circulating miRNA is a novel marker for head and neck squamous cell carcinoma. Tumour Biol. 2012;33:1933-1942.

70. Benderska N, Dittrich AL, Knaup S, et al. miRNA-26b overexpression in ulcerative colitis-associated carcinogenesis. Inflamm Bowel Dis. 2015;21:2039-2051.

71. Zhang C, Tong J, Huang G. Nicotinamide phosphoribosyl transferase (Nampt) is a target of microRNA-26b in colorectal cancer cells. PLoS One. 2013;8:e69963.

72. Fan D, Lin X, Zhang F, et al. MicroRNA 26b promotes colorectal cancer metastasis by down regulating phosphatase and tensin homolog and wingless-type MMTV integration site family member 5a. Cancer Sci. 2018;109:354-362.

73. Medrek C, Landberg G, Andersson T, Leandersson K. WNT-5a-CKI \{alpha\} signaling promotes $\{$ beta $\}$-catenin/E-cadherin complex formation and intercellular adhesion in human breast epithelial cells. J Biol Chem. 2009;284:10968-10979. 
74. Ma X, Meng Z, Jin L, et al. CAMK2gamma in intestinal epithelial cells modulates colitis-associated colorectal carcinogenesis via enhancing STAT3 activation. Oncogene. 2017;36:4060-4071.

75. Tobimatsu T, Fujisawa H. Tissue-specific expression of four types of rat calmodulin-dependent protein kinase II mRNAs. J Biol Chem. 1989;264:17907-17912.

76. Bui JD, Calbo S, Hayden-Martinez K, Kane LP, Gardner P, Hedrick SM. A role for CaMKII in $\mathrm{T}$ cell memory. Cell. 2000;100:457-467.

77. Huang W, Ghisletti S, Saijo K, et al. Coronin 2A mediates actin-dependent de-repression of inflammatory response genes. Nature. 2011;470:414-418.

78. Timmins JM, Ozcan L, Seimon TA, et al. Calcium/calmodulindependent protein kinase II links ER stress with Fas and mitochondrial apoptosis pathways. $J$ Clin Invest. 2009;119:2925-2941.

79. Bian Y, Chang X, Liao Y, et al. Promotion of epithelial-mesenchymal transition by Frizzled2 is involved in the metastasis of endometrial cancer. Oncol Rep. 2016;36 (2):803-810.

80. Gujral TS, Chan M, Peshkin L, Sorger PK, Kirschner MW, MacBeath G. A noncanonical Frizzled2 pathway regulates epithelial-mesenchymal transition and metastasis. Cell. 2014;159:844-856.

81. Maman S, Witz IP. A history of exploring cancer in context. Nat Rev Cancer. 2018;18:359-376.

82. Vitale I, Manic G, Coussens LM, Kroemer G, Galluzzi L. Macrophages and Metabolism in the Tumor Microenvironment. Cell Metab. 2019;30:36-50.

83. Ruffell B, Affara NI, Coussens LM. Differential macrophage programming in the tumor microenvironment. Trends Immunol. 2012;33:119-126.

84. Lee HW, Choi HJ, Ha SJ, Lee KT, Kwon YG. Recruitment of monocytes/macrophages in different tumor microenvironments. Biochim Biophys Acta. 2013;1835:170-179.

85. Liu Q, Song J, Pan Y, et al. WNT5a/CaMKII/ERK/CCL2 axis is required for tumor-associated macrophages to promote colorectal cancer progression. Int J Biol Sci. 2020;16:1023-1034.

86. Venkatachalam K, Montell C. TRP channels. Annu Rev Biochem. 2007;76:387-417.

87. Chen Z, Tang C, Zhu Y, et al. TrpC5 regulates differentiation through the $\mathrm{Ca} 2+/ \mathrm{WNT} 5 \mathrm{a}$ signalling pathway in colorectal cancer. Clin Sci (Lond). 2017;131:227-237.

88. Blume-Jensen P, Hunter T. Oncogenic kinase signalling. Nature. 2001;411:355-365.

89. Manning G, Whyte DB, Martinez R, Hunter T, Sudarsanam S. The protein kinase complement of the human genome. Science. 2002;298:1912-1934.

90. Li L, Ying J, Tong X, et al. Epigenetic identification of receptor tyrosine kinase-like orphan receptor 2 as a functional tumor suppressor inhibiting beta-catenin and AKT signaling but frequently methylated in common carcinomas. Cell Mol Life Sci. 2014;71:2179-2192

91. Mikels A, Minami Y, Nusse R. Ror2 receptor requires tyrosine kinase activity to mediate WNT5a signaling. J Biol Chem. 2009;284:30167-30176.

92. Chen Y, Bellamy WP, Seabra MC, Field MC, Ali BR. ERassociated protein degradation is a common mechanism underpinning numerous monogenic diseases including Robinow syndrome. Hum Mol Genet. 2005;14:2559-2569.

93. Saraswati S, Agrawal SS. Brucine, an indole alkaloid from Strychnos nux-vomica attenuates VEGF-induced angiogenesis via inhibiting VEGFR2 signaling pathway in vitro and in vivo. Cancer Lett. 2013;332:83-93.
94. Shi X, Zhu M, Kang Y, Yang T, Chen X, Zhang Y. WNT/betacatenin signaling pathway is involved in regulating the migration by an effective natural compound brucine in LoVo cells. Phytomedicine. 2018;46:85-92.

95. Aznar N, Ear J, Dunkel Y, et al. Convergence of WNT, growth factor, and heterotrimeric $\mathrm{G}$ protein signals on the guanine nucleotide exchange factor Daple. Sci Signal. 2018;11.

96. Mehdawi LM, Prasad CP, Ehrnstrom R, Andersson T, Sjolander A. Non-canonical WNT5a signaling up-regulates the expression of the tumor suppressor 15-PGDH and induces differentiation of colon cancer cells. Mol Oncol. 2016;10:1415-1429.

97. Kuhajda FP. Fatty-acid synthase and human cancer: new perspectives on its role in tumor biology. Nutrition. 2000;16(3):202-208.

98. Wang H, Xi Q, Wu G. Fatty acid synthase regulates invasion and metastasis of colorectal cancer via WNT signaling pathway. Cancer Med. 2016;5:1599-1606.

99. Chi P, Allis CD, Wang GG. Covalent histone modifications miswritten, misinterpreted and mis-erased in human cancers. Nat Rev Cancer. 2010;10:457-469.

100. Kim KH, Roberts CW. Targeting EZH2 in cancer. Nat Med. 2016;22:128-134. doi:10.1038/nm.4036

101. Tao J, Shi L, Huang L, et al. EZH2 is involved in silencing of WNT5a during epithelial-mesenchymal transition of colon cancer cell line. J Cancer Res Clin Oncol. 2017;143(11):2211-2219. doi:10.1007/s00432-017-2479-2

102. Wang J, Wang X, Liu F, Fu Y. microRNA-335 inhibits colorectal cancer HCT116 cells growth and epithelial-mesenchymal transition (EMT) process by targeting Twist1. Pharmazie. 2017;72 (8):475-481. doi:10.1691/ph.2017.7489

103. Yoon JK, Lee JS. Cellular signaling and biological functions of R-spondins. Cell Signal. 2012;24(2):369-377. doi:10.1016/j. cellsig.2011.09.023

104. Wu C, Qiu S, Lu L, et al. RSPO2-LGR5 signaling has tumour-suppressive activity in colorectal cancer. Nat Commun. 2014;5:3149. doi:10.1038/ncomms4149

105. Dong X, Liao W, Zhang L, et al. RSPO2 suppresses colorectal cancer metastasis by counteracting the WNT5a/Fzd7-driven noncanonical WNT pathway. Cancer Lett. 2017;402:153-165. doi:10.1016/j.canlet.2017.05.024

106. Truran PP, Johnson SJ, Bliss RD, Lennard TW, Aspinall SR. Parafibromin, galectin-3, PGP9.5, Ki67, and cyclin D1: using an immunohistochemical panel to aid in the diagnosis of parathyroid cancer. World J Surg. 2014;38(11):2845-2854. doi:10.1007/ s00268-014-2700-2

107. Zheng HC, Wei ZL, Xu XY, et al. Parafibromin expression is an independent prognostic factor for colorectal carcinomas. Hum Pathol. 2011;42(8):1089-1102. doi:10.1016/j.humpath.201 0.10 .024

108. Shen DF, Liu X, Yang XF, et al. The roles of parafibromin expression in ovarian epithelial carcinomas: a marker for differentiation and prognosis and a target for gene therapy. Tumour Biol. 2016;37(3):2909-2924. doi:10.1007/s13277-015-4103-X

109. Liu Y, Rubin B, Bodine PV, Billiard J. WNT5a induces homodimerization and activation of Ror2 receptor tyrosine kinase. $J$ Cell Biochem. 2008;105(2):497-502. doi:10.1002/jcb.21848

110. Lee JM, Kim IS, Kim H, et al. RORalpha attenuates WNT/ beta-catenin signaling by PKCalpha-dependent phosphorylation in colon cancer. Mol Cell. 2010;37(2):183-195. doi:10.1016/j. molcel.2009.12.022

111. Lin $\mathrm{X}, \mathrm{Xu} \mathrm{W}$, Shao M, et al. Shenling Baizhu San supresses colitis associated colorectal cancer through inhibition of epithelial-mesenchymal transition and myeloid-derived suppressor infiltration. BMC Complement Altern Med. 2015;15(1):126. doi:10.1186/s12906-015-0649-9 
112. Wang Z, Chen H. Genistein increases gene expression by demethylation of WNT5a promoter in colon cancer cell line SW1116. Anticancer Res. 2010;30(11):4537-4545.

113. Zhang Y, Chen H. Genistein attenuates WNT signaling by up-regulating sFRP2 in a human colon cancer cell line. Exp Biol Med (Maywood). 2011;236(6):714-722. doi:10.1258/ ebm.2011.010347

114. Zhang Y, Li Q, Zhou D, Chen H. Genistein, a soya isoflavone, prevents azoxymethane-induced up-regulation of WNT/beta-catenin signalling and reduces colon pre-neoplasia in rats. $\mathrm{Br} J$ Nutr. 2013;109(1):33-42. doi:10.1017/S0007114512000876

115. Zhang Y, Li Q, Chen H. DNA methylation and histone modifications of WNT genes by genistein during colon cancer development. Carcinogenesis. 2013;34(8):1756-1763. doi:10.1 093/carcin/bgt129

116. Lazarova DL, Bordonaro M, Carbone R, Sartorelli AC. Linear relationship between WNT activity levels and apoptosis in colorectal carcinoma cells exposed to butyrate. Int J Cancer. 2004;110 (4):523-531. doi:10.1002/ijc.20152

117. Bordonaro M, Lazarova DL, Sartorelli AC. The activation of beta-catenin by WNT signaling mediates the effects of histone deacetylase inhibitors. Exp Cell Res. 2007;313(8):1652-1666. doi:10.1016/j.yexcr.2007.02.008

118. Bordonaro M, Tewari S, Cicco CE, Atamna W, Lazarova DL. A switch from canonical to noncanonical WNT signaling mediates drug resistance in colon cancer cells. PLoS One. 2011;6: e27308. doi:10.1371/journal.pone.0027308

119. Zaid H, Silbermann M, Ben-Arye E, Saad B. Greco-arab and islamic herbal-derived anticancer modalities: from tradition to molecular mechanisms. Evid Based Complement Alternat Med. 2012;2012:349040. doi:10.1155/2012/349040

120. Lansky EP, Newman RA. Punica granatum (pomegranate) and its potential for prevention and treatment of inflammation and cancer. J Ethnopharmacol. 2007;109(2):177-206. doi:10.1016/j. jep.2006.09.006

121. Mertens-Talcott SU, Jilma-Stohlawetz P, Rios J, Hingorani L, Derendorf H. Absorption, metabolism, and antioxidant effects of pomegranate (punica granatum 1.) polyphenols after ingestion of a standardized extract in healthy human volunteers. $J$ Agric Food Chem. 2006;54(23):8956-8961. doi:10.1021/jf061674h

122. Sadik NA, Shaker OG. Inhibitory effect of a standardized pomegranate fruit extract on WNT signalling in 1, 2-dimethylhydrazine induced rat colon carcinogenesis. Dig Dis Sci. 2013;58:2507-2517. doi:10.1007/s10620-013-2704-z

123. Safholm A, Leandersson K, Dejmek J, Nielsen CK, Villoutreix BO, Andersson T. A formylated hexapeptide ligand mimics the ability of WNT-5a to impair migration of human breast epithelial cells. J Biol Chem. 2006;281(5):2740-2749. doi: $10.1074 /$ jbc.M508386200

124. Safholm A, Tuomela J, Rosenkvist J, Dejmek J, Harkonen P, Andersson T. The WNT-5a-derived hexapeptide Foxy- 5 inhibits breas cancer metastasis in vivo by targeting cell motility. Clin Cancer Res. 2008;14:6556-6563. doi:10.1158/1078-0432.CCR-08-0711

125. Osman J, Bellamkonda K, Liu Q, Andersson T, Sjolander A. The WNT5a Agonist Foxy5 Reduces the Number of Colonic Cancer Stem Cells in a Xenograft Mouse Model of Human Colonic Cancer. Anticancer Res. 2019;39:1719-1728. doi:10.21873/anticanres.13278

126. Santoro A, Pisanti S, Grimaldi C, et al. Rimonabant inhibits human colon cancer cell growth and reduces the formation of precancerous lesions in the mouse colon. Int $J$ Cancer. 2009;125:996-1003. doi:10.1002/ijc.24483

127. Gustafsson SB, Lindgren T, Jonsson M, Jacobsson SO. Cannabinoid receptor-independent cytotoxic effects of cannabinoids in human colorectal carcinoma cells: synergism with 5-fluorouracil. Cancer Chemother Pharmacol. 2009;63:691-701. doi:10.1007/s00280-008-0788-5
128. Gazzerro P, Malfitano AM, Proto MC, et al. Synergistic inhibition of human colon cancer cell growth by the cannabinoid CB1 receptor antagonist rimonabant and oxaliplatin. Oncol Rep. 2010;23:171-175.

129. Proto MC, Fiore D, Piscopo C, et al. Inhibition of WNT/ beta-Catenin pathway and Histone acetyltransferase activity by Rimonabant: a therapeutic target for colon cancer. Sci Rep. 2017;7(1):11678. doi:10.1038/s41598-017-11688-x

130. Wei W, Sun HH, Li N, et al. WNT5a modulates cell cycle progression and contributes to the chemoresistance in pancreatic cancer cells. Hepatobiliary Pancreat Dis Int. 2014;13 (5):529-538. doi:10.1016/S1499-3872(14)60277-0

131. Jiang G, Lin J, Wang W, Sun M, Chen K, Wang F. WNT5a promoter methylation is associated with better responses and longer progression-free survival in colorectal cancer patients treated with 5-fluorouracil-based chemotherapy. Genet Test Mol Biomarkers. 2017;21:74-79. doi:10.1089/gtmb.2016.0162

132. Yin L, Grandi N, Raum E, Haug U, Arndt V, Brenner H. Metaanalysis: longitudinal studies of serum vitamin $\mathrm{D}$ and colorectal cancer risk. Aliment Pharmacol Ther. 2009;30(2):113-125. doi:10.1111/j.1365-2036.2009.04022.x

133. Feldman D, Krishnan AV, Swami S, Giovannucci E, Feldman BJ. The role of vitamin D in reducing cancer risk and progression. Nat Rev Cancer. 2014;14(5):342-357. doi:10.1038/nrc3691

134. Groschel C, Aggarwal A, Tennakoon S, et al. Effect of 1,25-dihydroxyvitamin D3 on the WNT pathway in non-malignant colonic cells. J Steroid Biochem Mol Biol. 2016;155:224-230. doi:10.1016/j.jsbmb.2015.02.011

135. Ghosh-Choudhury N, Mandal CC, Ghosh-Choudhury N, Ghosh Choudhury G. Simvastatin induces derepression of PTEN expression via NFkappaB to inhibit breast cancer cell growth. Cell Signal. 2010;22(5):749-758. doi:10.1016/j.cellsig.2009.12.010

136. Fang Z, Tang Y, Fang J, et al. Simvastatin inhibits renal cancer cell growth and metastasis via AKT/mTOR, ERK and JAK2/ STAT3 pathway. PLoS One. 2013;8(5):e62823. doi:10.1371/journal.pone. 0062823

137. Cho SJ, Kim JS, Kim JM, Lee JY, Jung HC, Song IS. Simvastatin induces apoptosis in human colon cancer cells and in tumor xenografts, and attenuates colitis-associated colon cancer in mice. Int J Cancer. 2008;123(4):951-957. doi:10.1002/ijc.23593

138. Gopalan A, Yu W, Sanders BG, Kline K. Simvastatin inhibition of mevalonate pathway induces apoptosis in human breast cancer cells via activation of JNK/CHOP/DR5 signaling pathway. Cancer Lett. 2013;329(1):9-16. doi:10.1016/j.canlet.2012.08.031

139. Lu L, Huang W, Hu W, et al. Kruppel-like factor 2 mediated anti-proliferative and anti-metastasis effects of simvastatin in p53 mutant colon cancer. Biochem Biophys Res Commun. 2019;511 (4):772-779. doi:10.1016/j.bbrc.2019.02.127

140. Ciappio ED, Liu Z, Brooks RS, Mason JB, Bronson RT, Crott JW. Maternal B vitamin supplementation from preconception through weaning suppresses intestinal tumorigenesis in Apc1638N mouse offspring. Gut. 2011;60(12):1695-1702. doi:10.1136/gut.2011.240291

141. Katoh M. WNT/PCP signaling pathway and human cancer (review). Oncol Rep. 2005;14(6):1583-1588.

142. Gao Y, Zhao H, Wang P, et al. The roles of SOCS3 and STAT3 in bacterial infection and inflammatory diseases. Scand J Immunol. 2018;88(6):e12727. doi:10.1111/sji.12727

143. Balanis N, Wendt MK, Schiemann BJ, Wang Z, Schiemann WP, Carlin CR. Epithelial to mesenchymal transition promotes breast cancer progression via a fibronectin-dependent STAT3 signaling pathway. J Biol Chem. 2013;288(25):17954-17967. doi:10.1074/ jbc.M113.475277

144. Kim JH, Kang GH. Evolving pathologic concepts of serrated lesions of the colorectum. J Pathol Transl Med. 2020;54 (4):276-289. doi:10.4132/jptm.2020.04.15 
145. Ogino S, Goel A. Molecular classification and correlates in colorectal cancer. J Mol Diagn. 2008;10(1):13-27. doi:10.2353/ jmoldx.2008.070082

146. Ogino S, Nosho K, Kirkner GJ, et al. CpG island methylator phenotype, microsatellite instability, BRAF mutation and clinical outcome in colon cancer. Gut. 2009;58(1):90-96. doi:10.1136/ gut.2008.155473

147. Kim JH, Shin SH, Kwon HJ, Cho NY, Kang GH. Prognostic implications of $\mathrm{CpG}$ island hypermethylator phenotype in colorectal cancers. Virchows Arch. 2009;455(6):485-494. doi:10.1007/ s00428-009-0857-0

148. Dahlin AM, Palmqvist R, Henriksson ML, et al. The role of the $\mathrm{CpG}$ island methylator phenotype in colorectal cancer prognosis depends on microsatellite instability screening status. Clin Cancer Res. 2010;16:1845-1855. doi:10.1158/1078-0432.CCR-09-2594

149. Ribic CM, Sargent DJ, Moore MJ, et al. Tumor microsatellite-instability status as a predictor of benefit from fluorouracil-based adjuvant chemotherapy for colon cancer. $N \mathrm{Engl}$ J Med. 2003;349(3):247-257. doi:10.1056/NEJMoa022289

150. Carethers JM, Smith EJ, Behling CA, et al. Use of 5-fluorouracil and survival in patients with microsatellite-unstable colorectal cancer. Gastroenterology. 2004;126(2):394-401. doi:10.1053/j. gastro.2003.12.023
151. Rawson JB, Mrkonjic M, Daftary D, et al. Promoter methylation of WNT5a is associated with microsatellite instability and BRAF V600E mutation in two large populations of colorectal cancer patients. $\mathrm{Br}$ J Cancer. 2011;104(12):1906-1912. doi:10.1038/bjc.2011.165

152. Wang Y. WNT/Planar cell polarity signaling: a new paradigm for cancer therapy. Mol Cancer Ther. 2009;8(8):2103-2109. doi:10.1158/1535-7163.MCT-09-0282

153. Dejmek J, Dejmek A, Safholm A, Sjolander A, Andersson T. WNT-5a protein expression in primary dukes $\mathrm{B}$ colon cancers identifies a subgroup of patients with good prognosis. Cancer Res. 2005;65 (20):9142-9146. doi:10.1158/0008-5472.CAN-05-1710

154. Ahn JB, Chung WB, Maeda O, et al. DNA methylation predicts recurrence from resected stage III proximal colon cancer. Cancer. 2011;117(9):1847-1854. doi:10.1002/cncr.25737

155. Kim SH, Park KH, Shin SJ, et al. CpG island methylator phenotype and methylation of wnt pathway genes together predict survival in patients with colorectal cancer. Yonsei Med J. 2018;59(5):588-594. doi:10.3349/ymj.2018.59.5.588

156. Kamposioras K, Konstantara A, Kotoula V, et al. The prognostic significance of WNT pathway in surgically-treated colorectal cancer: beta-catenin expression predicts for disease-free survival. Anticancer Res. 2013;33(10):4573-4584.

\section{Publish your work in this journal}

Cancer Management and Research is an international, peer-reviewed open access journal focusing on cancer research and the optimal use of preventative and integrated treatment interventions to achieve improved outcomes, enhanced survival and quality of life for the cancer patient.
The manuscript management system is completely online and includes a very quick and fair peer-review system, which is all easy to use. Visit http://www.dovepress.com/testimonials.php to read real quotes from published authors. 